\title{
Moving From Fragmented to Seamless Sense-Making in Blended Learning
}

\author{
Bi Xiaofang $^{*}$ \\ Institute for Adult Learning, Singapore University of Social Sciences, 11 Eunos Road 8, \\ \#07-04 Lifelong Learning Institute, Singapore 408601
}

Received: 8 March 2021, Accepted: 25 May 2021

\begin{abstract}
Context: Sense-making, understood as meaning making or giving meaning to experience, is an integral part of everyday life, work and learning, and is a process critical in enabling people to recognise how and when to respond to situations appropriately so that they can resolve problems effectively. Earlier studies on sense-making in educational or organizational settings tended to focus on the sense-making process per se in particular setting such as classrooms or organizations, few of them have paid much attention to the sense-making process in blended learning (BL). BL in vocational training mainly aims to enable adult learners to apply what was learnt in classrooms to solve authentic problems in workplaces or simulated settings. High quality of sense-making is crucial to help the learners achieve the aim. This timely study is to offer a comparative look at how different dynamics of BL interplay together to mediate the quality of sense-making in achieving learning outcomes. The dynamics include industry and training connections, policy and institutional contexts, the inhabited pedagogical practices and curriculum design.
\end{abstract}

Methods: This study adopted phenomenological and semi-ethnographic approaches, including semi-structured interviews, observations, analysis of relevant documents (e.g. curriculum and learning materials) to capture the rich data in case studies to understand learners' sense-making experience in BL. Researchers focused on seeking to understand how different environments, tools and artefacts mediate the quality of sense-making as the learners progressed through their learning journey. To triangulate the data, adult educators, curriculum

*Corresponding author: bi_xiaofang@ial.edu.sg 
designers and where possible, workplace supervisors, were also interviewed and observed for their perceptions and behaviours in learners' sense-making in BL.

Findings: The findings from two different BL courses (ICT and HR) surface that the degree to which learners' sense-making is fragmented (low quality) or seamless (high quality) is mediated by the interplay of different contextual factors in BL in multiple ways, such as, the connections (or not) with industry, the use (or not) of authentic problems and tasks.

Conclusion: The interplay between different dynamics in BL is of great importance to mediate the curriculum design and pedagogical approaches used in BL for high quality of sense-making of adult learners in vocational training.

Keywords: Sense-Making, Blended Learning, Curriculum Design and Pedagogies, Vocational Education and Training, VET

\section{Introduction}

Sense-making is understood as finding a way of thinking about diversity, complexity, uncertainties, ambiguities and incompleteness (Dervin, 1998). Building on Dervin's early work, educational (e.g., Harverly et al., 2020) and organizational studies (Weick, 1995; Weick et al., 2005) argue that sense-making is a sociocultural and cognitive process by which students/ teachers/workers in educational or organizational settings interactively and dialogically make meanings and plausible explanations of their collective experiences of uncertainties or ambiguities. In educational settings, researchers claim that sense-making is a process in which students co-construct their understanding of the world as they generate, use, and extend their ideas in the classroom (Maskiewicz \& Winters, 2012).

In this article, I explore how different sense-making features are distributed in two different blended learning courses: Information, Communication and Technology (ICT) and Human Resource Management (HR Management) to bring about different quality of sensemaking, namely fragmented or seamless, for the learners in these courses. Additionally, I examine the impact of mediating factors, such as industry and Training and Adult Education (TAE) contexts, design and delivery of courses, on the quality of learners' sense-making in BL. The semi-ethnographic study (Bi et al., 2020) of six different courses by different training providers, which this article refers to, was conducted in Singapore to investigate how adult learners experience and translate sense-making across different blended environments. 


\section{$2 \quad$ Sense-Making and Learning}

Sense-making in this article is conceptualised as a cognitive, sociocultural process. Sensemaking occurs when people encounter something that is abstract, confusing, uncertain or new (Malitis \& Christianson, 2014; Weick et al., 2005). The process is described as ongoing; there is no clear stop and start point. The absence of a beginning (or end) in sense-making means that people may not always consciously make sense of things - they just do so, as events unfold within their experience (Weick et al., 2005). Dialogue and interaction are integral to collective sense-making (Maskiewicz \& Winters, 2012; Weick et al., 2005), and serve as a springboard to action (Albolino et al., 2007).

Weick et al (2005) identify features of sense-making as; noticing difference (resulting from, for example, feelings of uncertainty, that something is not quite right, new or abstract), followed by attempts at categorising and then labelling (naming) what is happening. The environment where sense-making takes place influences such processes, e.g. previous actions of self and others, protocols that "need" to be followed, the culture of the organisation. Thus sense-making is distributed across the organisation systemically. The next question asked in the process of sense-making is "What do I/we do now?" This is the action part of sensemaking which is important in organizational sense-making; it always involves talking with others; thus communication is central to sense-making as a social process. In sum, sensemaking,

1. Is noticing and bracketing organizing chaos;

2. Is about labelling and categorizing to stabilize the stream of experiences;

3. Is retrospective;

4. Connects abstract knowledge with the concrete instances;

5. Is social and systemic;

6. Is about organizing through communication; and

7. Is about what actions to take (Weick et al., 2005).

The different sense-making features identified in organizational studies represent strongly how sense-making is both a cognitive and a social process. For instance, when noticing the differences and labelling such differences in retrospective ways, workers may mainly rely on their own cognitive thinking to figure out unfamiliar scenarios. However, such scenarios are not existing independently within an organization, it may be related to other systemic phenomenon within the organization, therefore, individuals may have to make sense of such un- 
familiar scenarios in a more holistic and systemic way situated in organizational culture. Inevitably, workers have to communicate with the people around in these unfamiliar scenarios to check if they are on the right track, e.g., their supervisors, peers in the organization. Therefore, sense-making is not only individualised but also collective. In the meantime, workers may take some actions to experiment their observations and interpretations in the unfamiliar scenarios. It is worthy to note that these features are not occurring in a linear way, all of them may occur iteratively without a start or a stop, particularly in the changing organizations. As a result, sense-making emerges as a critical capability for workers to quickly adapt and adjust to the constant changes in organizations. However, organizational studies on sense-making tended to only focus on such process per see, but not the quality of it and how organization discourse and practice may mediate such a process.

Another body of literature related to learning shows some implicit links with sense-making. Vygotsky's work provides a useful link, but somewhat different perspective from the work of Weick and others. Vygotsky's work was aimed at "generating an account of learning in which mind is making sense and externalising understandings by acting on the world using the tools available to change it for the better" (Edwards, 2010, p. 6). Action is mediated by the cultural and physical resources in our environments (contexts). Language and thus communication are such cultural tools that mediate actions, which finds some common ground with Weick et al's (2005) account of sense-making. Lave (1988) notes that cognition in everyday practice is distributed over mind, body and settings. Researchers such as Lave and Edwards, highlight the importance of mediation by cultural and physical tools in cognitive processes. Weick et al.s (2005) sense-making features such as noticing, categorising, retrospectivity and so on, shows strong links with cognitive theories which provide further insights into sensemaking. Kolb's experiential learning theory (1984) has been used in studies of high reliability organisations (Owen, 2009a, 2009b, 2017), suggesting it may offer more enlightening insights for the links between learning and sense-making.

Kolb's classical experiential learning theory (1984) comprises four elements: Experience, reflection, conceptualisation and experimentation. There is considerable connection between the four elements and the features of sense-making as listed from Weick et al's (2005) work. Ambiguity, confusion, uncertainty is a result of new experience; reflection and conceptualisation are where individuals and collectives look back, recall, make comparisons to begin the process of naming, categorising, linking to what is known from their own experiences and from theory; and active experimentation is putting that meaning-making into action. Such explicit connections show that Kolb's elements of experiential learning theory can be readily linked to sense-making processes as outlined by Weick et al. (2005). As a result, the strong links between sense-making and learning are well established in Kolb's work.

Though the strong links with learning, there is more to sense-making that needs to be understood. Firstly, sense-making is mediated by contexts. As Edwards (2010) and Lave (1988) 
highlight, cognition is a socio-cultural process. Weick et al. (2005) identify culture and rules of an organisation in which sense-making occurs, naming this process as social and systemic, suggesting that sense-making is not just influenced by context, but mediated. Within any given contexts, the cultural, social and material factors all influence individual and collective sense-making, including actions which in turn influence the context/environment. Secondly, sense-making is an important capability for workers to solve authentic problems in order to adapt to the constantly changing needs at workplaces. From this perspective, sense-making is more than understanding and interpreting the uncertainties in unfamiliar scenarios, but with more emphasis on the appropriate actions that workers could be able to take to tackle the authentic problems, particularly those related to workplace practice. Therefore, sensemaking emerges as an applicable and critical concept for further investigation in vocational training.

\section{Why Sense-Making Matters in Blended Learning}

With the advancement of educational technology, BL has been prevalent for the past two decades mainly in higher educational settings with the combination of both classroom and e-learning to meet the diverse learning needs and provide more access to learning. Numerous studies have been conducted to focus on the mediation of various factors, e.g. design features (technology quality, face-to-face support and learning management system and resources) (Beard et al., 2004; Kintu et al., 2017; Piccoli et al., 2001; Willging \& Johnson, 2009); pedagogical approaches (Chen et al., 2019; Koh et al., 2016; Shorey et al., 2018; Strayer et al., 2015) and curriculum design in BL (Ahmad \& Orion, 2010; Bhatti \& Kaur, 2010; Koponen et al., 2011; Gleadow et al., 2015; Scardamalia \& Bereiter, 2015; Velada et al., 2007; Korhonen et al., 2020) on BL experience and outcomes. For example, flipped-classroom approach has been widely used in BL in Singapore and international higher education contexts. However, the approach itself does not necessarily work well to achieve learning outcome if without deliberate curation of contents by educators to link classroom and e-learning. Without such deliberate curation, e-learning may only be used as a form of database to download learning materials (Chen et al., 2019). Equally important is the design of BL. Simply putting classroom and e-learning together without thinking about the learning needs of the learners and purpose of BL may cause challenges for learners to achieve their learning outcome. For example, face-to-face experiences form part of BL and learners' favour for such sessions may lead to better learning outcomes. Beard, Harper and Riley (2004) shows that some learners are successful while in a personal interaction with teachers and peers thus prefer face-to-face in the BL. In addition, the design of the activities in BL is of great importance to establish links across the different settings (Gleadow et al., 2015) to enable learners to achieve the desired learning outcome. 
Relating BL to TAE, the components of $\mathrm{BL}$ have been broadened to include (simulated) workplace learning in many cases, but not all (IAL, 2016). Besides providing easy access and meeting different learning needs, one of the most desired purposes of BL in TAE is to enable the adult learners to take actions in applying theory into practice, so they are able to solve authentic problems at their own workplaces. Therefore, the concept of sense-making becomes highly relevant to $\mathrm{BL}$ in TAE, as its action feature is able to achieve such purpose. A common assumption is that including (simulated) workplace learning in BL may bring about the application and connection between theory and practices automatically (Chen et al., 2019). Such assumptions are misguided, as it is not the different settings but changed beliefs, provision of institutional support and opportunity that have an important role to play in changing pedagogical practices and curriculum design to mediate learners' sense-making quality in BL. More deliberate design and pedagogical practices in BL for TAE need to be planned and structured by considering the interplay of the dynamics beyond, e.g., broader industry and TAE contexts, policy and institutional contexts. However, until recently few studies have delved deeply into this area on the mediation of interplay of dynamics of $\mathrm{BL}$ on the quality of sense-making. Bearing in mind the distinctive features of sense-making as discussed in Section 2, therefore, the broadened BL in TAE pushes us to seek a more holistic understanding of how the dynamics of BL interplay to mediate the quality of sense-making.

This article makes a timely attempt to fill this gap. The study (Bi et al., 2020) on which this article is based, took place in Singapore where the government agency responsible for workforce development, SkillsFuture Singapore, was pushing forward an agenda to move from predominantly classroom-based delivery (Bound \& Lin, 2011) to recognising and valuing workplace learning and using technology as an enabler for learning in and across classroom and work environments. A recent policy development, iN. LEARN (2020) emphasises the importance of promoting BL in Singapore's Continuing Education and Training (CET) (similar to Vocational Education and Training), as a way to enhance learners' access to learning and to meet their dynamic learning needs for the purposes of development for and in work. More specifically, BL in Singapore context consists of any combination of two or more components from classroom, tech-enabled, workplace learning spaces. In addition, to the ways in which these policies mediate use of technology, learning design and so on, remain unclear to us.

Therefore, a deep and holistic understanding of how the interplay of the dynamics of $\mathrm{BL}$ mediates the quality of sense-making is needed both theoretically and empirically. To fill this gap, specifically, this article aims to investigate the following questions:

1. What are adult learners' sense-making experiences in different BL courses?

2. How are different mediating factors working together for different sense-making experiences of adult learning in different BL courses? 


\section{$4 \quad$ Methodology}

This study was drawn on different qualitative approaches to study adult learners' sensemaking in BL; namely, phenomenology and semi-ethnography. Literally, phenomenology is the study of "phenomena": Appearances of things, or things as they appear in our experience, or the ways we experience things, thus the meanings things have in our experience (Woodruff, 2018). A phenomenological approach provides rich descriptive data capturing the phenomena of learners' sense-making. A semi-ethnographic approach provides an interpretive lens moving beyond the rich description and themes identified from the phenomenological data collection and analysis (Hammersley, 2010), allowing an analysis of enablers and constraints on learners' sense-making.

The unit of analysis in the two case studies is learners' sense-making experience in and across blended learning environments (Bi et al., 2020). The two BL courses, across two industry sectors (ICT and HR Management) were selected because of adult learners' distinctive sense-making experience in the courses, the comparison of these courses provides a rich description of the different impact of the mediating factors on learners' sense-making. In each BL course selected, three to four individual learners (anonymised) from each course were invited to participate in the study upon their consent. Semi-structured interviews, observations, and analysis of relevant documents (e.g. curriculum and learning materials) enable the capturing of rich data to understand learners' sense-making experience. Each selected learner was interviewed and observed at least two or three times throughout their entire course. Through these data, researchers focused on seeking to understand how different environments, tools and artefacts mediate the activity of sense-making as the learners progressed through their learning journey. To triangulate the data, adult educators, curriculum designers and where possible, workplace supervisors, were also interviewed and observed for their perceptions and behaviours in learners' sense-making in BL.

Table 1: Participants in the Two Selected Courses

\begin{tabular}{|l|l|l|l|l|l|l|l|}
\hline $\begin{array}{l}\text { Industries/ } \\
\text { Courses }\end{array}$ & Learners & $\begin{array}{l}\text { Adult } \\
\text { Educators }\end{array}$ & $\begin{array}{l}\text { Curriculum } \\
\text { Designers }\end{array}$ & $\begin{array}{l}\text { Workplace } \\
\text { Supervisors }\end{array}$ & $\begin{array}{l}\text { No of } \\
\text { Interviews }\end{array}$ & $\begin{array}{l}\text { No of } \\
\text { Participant } \\
\text { Observations }\end{array}$ \\
\hline ICT & 1 & 4 & 1 & 1 & 0 & 10 & 3 \\
\hline $\begin{array}{l}\text { HR } \\
\text { Management }\end{array}$ & 1 & 4 & 3 & 1 & 0 & 12 & 4 \\
\hline Total & 2 & 8 & 4 & 2 & 0 & 22 & 7 \\
\hline
\end{tabular}

During preliminary data analysis using the seven features developed by Weick et al. (2005), it was found the seven features of sense-making identified in organizational studies need to be adapted and more nuanced in the setting of BL than the list provided earlier. Therefore, 
the present study refined the seven features to better cater to the data analysis of the present study. Table 2 provides an explanation of each of the refined features evident in the data in the present study. These refined seven features were used to analyse adult learners' sense-making in the present study.

Table 2: Sense-Making Features Reconfigured in the Present Study

\begin{tabular}{|l|l|}
\hline Sense-Making Features & Explanation \\
\hline Noticing & $\begin{array}{l}\text { A process of observing, identifying and experiencing similarities and differences } \\
\text { across various situations, conditions and contexts. }\end{array}$ \\
\hline Recalling & A process of recollecting, reconsidering and deliberating on past experiences. \\
\hline Labelling & $\begin{array}{l}\text { A process of grouping, comparing, naming and evaluating observed similarities } \\
\text { and differences in knowledge learnt, conditions and contexts. }\end{array}$ \\
\hline Connecting & $\begin{array}{l}\text { A process of making efforts to link the theoretical and practical knowledge, } \\
\text { individually or collectively. }\end{array}$ \\
\hline Conceiving a systemic understanding & $\begin{array}{l}\text { Developing ways of thinking to deepen understanding of aspects of professional } \\
\text { concepts and practice within a wider context. }\end{array}$ \\
\hline Communicating & $\begin{array}{l}\text { Social and inter-personal processes to further understand what is learnt, e.g., } \\
\text { asking questions, posing considerations, predicting, seeking clarifications. }\end{array}$ \\
\hline Taking action & Iteratively translating / applying the sense-made, and reflecting. \\
\hline
\end{tabular}

The seven features of sense-making do not take place in BL always in linear sequence and in equal distribution. In different instances of sense-making, some features are more or less interrelated, more or less iterative, and some features may occur more frequently than the rest. For example, communicating tends to be interrelated more with the rest of the features and is thus a relatively prevalent feature in the sense-making process. In the literature discussed above, action is an outcome of the sense-making process, and as in Kolb's elements, may result in repetitions of sense-making processes. It is therefore useful to capture frequency of different features, as captured in Figure 1 and 2. These pie charts were generated by coding the observation and interview data to calculate the frequencies of different sense-making features evident in the data. As a result of different distribution of sense-making features, the adult learners in different BL courses tend to have fragmented or seamless sense-making as illustrated in the findings below. In addition, the various factors, e.g., the delivery and design of the courses, the partnership between training providers and employers, mediating the distributions are also explored to explain why different distributions of sense-making features in these BL courses are evident. 


\section{Results}

The analysis of classroom observation transcripts and interview transcripts with adult learners, adult educators and curriculum designers in the two selected BL courses demonstrated how the different patterns of seven sense-making features may bring about different quality of sense-making for learner in these courses. The reasons behind the different patterns of sensemaking features were also explored from the perspectives of the design and delivery of these courses.

\subsection{ICT Learners: Why I am not so Confident to Apply What I Have Learnt in Classroom Into my Workplaces?}

For ICT course, the training provider claims that the learner will gain in-depth knowledge of how SAP (System, Application, Products) ERP systems support business operations within specific functional or technical domains in an enterprise. With the certificate gained on completion of this course, learners are expected to be able to work as a SAP consultant whose job scope is to maintain the components and functionalities for SAP applications to fulfil customer's demand and to customize SAP applications to find and fix issues and recover the original functionality. The course is structured so that learners are engaged in e-learning (80\%), and they have 24/7 access to e-contents for each module for one month. Learners who need help can approach tutors during tutorial sessions, where they are provided with oneto-one support regarding the course materials or technical matters. The remaining course (20\%) was conducted via face-to-face flipped class lectures aimed at providing guidance to make sure that the learners are learning the correct skills and knowledge by themselves in e-learning.

However, at the end of the course, the learners shared that they still lacked the competence and confidence to apply for relevant jobs mainly because they were not provided with opportunities to apply what they have learnt nor had they experienced application in authentic settings. Their sense-making process as represented in Figure 1 explains why. Figure 1 is drawn according to the distributions of the different sense-making features in ICT learners' sensemaking processes. Besides the distribution of these features, the interrelationship among the features is also marked by the dotted line. The interrelationship among the features means that different features may occur together in their sense-making, rather than independently all the time. Please refer to the legend in the figure. 


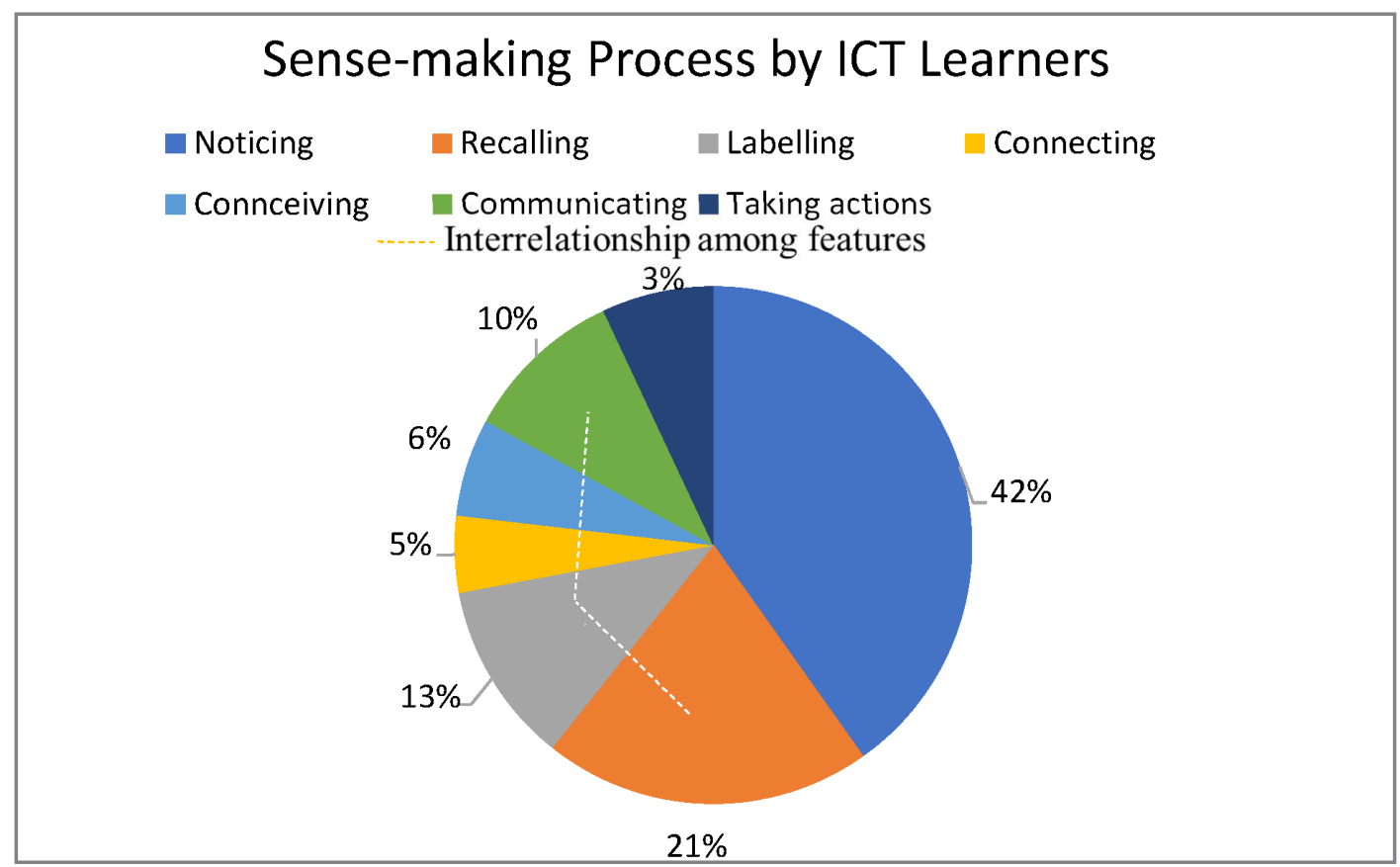

Figure 1: Sense-Making Process by ICT Learners

Figure 1 shows the adult learners in this ICT course spent most of their time noticing differences (42\%), recalling past experience (21\%) and making comparisons and labelling (13\%). Comparatively, they seldom connected theory with practice (5\%), or conceived a systemic understanding of the SAP program in relation to their organisation(s) or the context of their industry (6\%). Another less evident feature in the data was taking actions to apply what they learnt $(3 \%)$. All of the learners in this course spent much time recalling their past experience of using accounting systems and trying to identify the differences between the old and new systems, as well as identifying the discrepancies between the actual learning in the course and their expectations based on the enrolment information. The dotted line indicates that the sense-making features connected by the dotted line take place concurrently. In this instance, recalling and labelling, communicating and labelling. This suggests that their sensemaking process are not well linked with different features, and thus limited.

Apple (one of the ICT course learners) commented that there was a mismatch between the learning outcomes as claimed by the training provider and what was experienced by herself.

Their (school) aim is to equip the student to be an SAP consultant. I can tell you that it's really not up to the standard, if let's say you really want to have an allrounded SAP. Unless you say that this consultant only focus on FI (Finance) and only asking question and translating the question to the SAP consultant. However, even so, we can only do the FI part, not the MM (Materials Management) or SD 
(Sales and Distribution) part. Just one part, so is it enough? Obviously if let's say like I said, unless you label this consultant only do FI, only do certain part. Otherwise, if you just put SAP consultant, I think, cannot. You don't even know the MM or $S D$. (Apple, Learner from ICT course)

Another learner, Sunny, had the same experience, stating that he did not feel qualified as a SAP consultant after the course even though the training provider would certify them as a SAP consultant:

Yes, user-wise, there is enough experience for me. Now I can do post journal, everything that's basically what you need to be an accountant, as a user. They are teaching more as a user, than to be a consultant, but I don't think they have reached that level yet. Only classroom consultant yes, workplace consultant I don't think so... But you are certified as a consultant, you understand? Unless you have workplace exposure, experience, how the system works in the workplace, then you can be straightaway a consultant, junior consultant. But my company doesn't even use this system, I only have classroom experience [...]. And if I go to the company and say that I am an expert at this, which is ridiculous, I am only a classroom expert. (Sunny, Learner from ICT course)

In addition to the insufficient content coverage, Sunny also commented that such a mismatch may also be due to the lack of workplace exposure or experience of using the SAP ERP system. Such a comment echoed the low frequency of the feature of 'connecting' in ICT learners' sense-making. As shown in Figure 1, "connecting" appeared far less frequently in the all the sense-making features. This was mainly due to use of classroom and e-learning spaces, with no workplace learning or real case scenarios involved. The exercises the learners completed on the e-learning platform were not authentic and versatile enough for them to feel confident that they can become a SAP consultant in a company, as shown in another learner's (Berry) sharing:

They are using the e-books which provided by SAP, so the requirement by the SAP is, that is a very good yardstick, so you really have to make sure you know all these things so it's good, another one is the, for us, practical session one, that is SAP assessed, okay, for us to assume this is a SAP software when you go to a company, this is for you to data entry, which is good, but we need someone to tell us in real life this can be done in this way but you can also, you have to be apply this book's knowledge and, to the real case job scenario. You mention that hospitals, that type of practical session so it's...Here don't have, that is the gap. (Berry, Learner from ICT course) 
Without authentic application of a SAP ERP system, Berry further shared that she was not confident to apply for a relevant job with the certificate obtained from this course. The lack of such a component in this blended learning course may also contribute to low frequency of connecting theoretical knowledge and authentic practices by these learners. For example, all the examples in e-learning platform for learners to practice were designed strictly following the exercise on the textbook, which all the learners in this course felt that such exercises were out of their working context which requires a lot of customization for specific workplaces.

Learner's experience of BL in this course was one of frustration, and a huge gap between the promised outcomes and the reality of the course not equipping them to become SAP consultants as promised in the course materials. Basics such as systems failures, not being able to download materials readily, the reliance on workbooks, and the requirement that learners had to complete modules in a short time frame were all common complaints contributing to a focus on the lower quality of sense-making. Such complaints indicate disrupted and fragmented experiences hindering these learners to make a conceptualization of a systemic understanding of how the SAP ERP system may apply to their specific workplaces. Their sense-making was relegated to a kind of rote learning to ensure the right buttons in the SAP ERP system were clicked. Learners' comments that there was no opportunity to apply theory to practice suggest this is a missing element in the course design. What was taught in the course did not incorporate the versatility of the SAP system and the ways in which it can be applied differently in different settings. Instead, the course design and facilitation were very prescriptive where learners had to strictly follow the procedural steps.

\subsection{Why Fragmented Sense-Making for ICT Learners?}

The observation of the flipped classroom learning explained such fragmented sense-making for learners. During our observation, researchers noticed few classroom interactions between adult educator and learners or between learners took place. The classroom teaching was quite monologue with one-way feeding by the adult educator, who dominated and controlled the instruction content and pace. In such didactic teaching (Walklin, 1990), learners were seldom encouraged to ask questions, and share knowledge in some activities, e.g. groupwork discussions. Without the deliberate pedagogical approaches designed to encourage the learners to ask questions and share with each other about their own workplace experience (Chen et al., 2019), learners may lose the opportunism to make connections between theory and practice in order to be more competent to use SAP in their own workplaces (Gleadow et al., 2015).

Consequently, there was limited opportunity to develop a deep understanding of the possibilities for the deployment of SAP system in a company, which was the promised learning outcomes at the end of the course. Learners reported instead that they could only be a user, not operate at the higher level of consultant. Therefore, the learners explained that 
the curriculum content was not adequate to meet most employer's needs and requirements in the industry. They strongly recommended that some embedded hands-on learning in between classroom and e-learning was necessary to help them achieve a holistic understanding of deploying SAP ERP system and be more competent and confident in applying for related jobs. Additionally, there appeared to be limited opportunity for learners to engage in purposeful dialogue. The following figure represents the fragmented sense-making experience of ICT learners in this course.

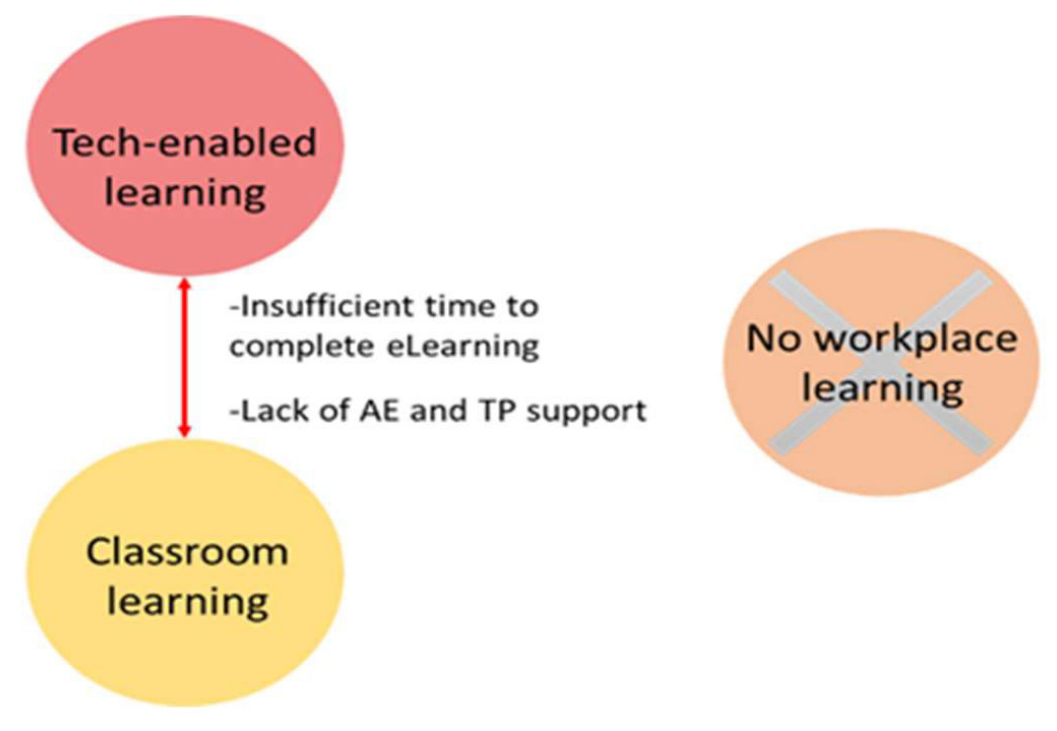

Figure 2: ICT Learners' Fragmented Sense-Making Experience in Blended Learning

The lack of clarity on the purpose of using BL is a contributing factor to the fragmented sense-making experience of these ICT learners and of their limited sense-making opportunities. At the time of data collection for this course, the course had been run by the training provider for six years, however BL had been in place for only six months. Before this, the course was delivered purely by classroom teaching over a nine-month period. The change into BL was the Provider's interpretation of policy changes; namely the government initiative to incorporate blended learning in all full qualification WSQ (Workforce Skills Qualifications) courses by Jan, 2017 in order to maintain the training provider's training subsidy. With such a change, the training provider appeared not sufficiently prepared to take learners' needs and capability development into consideration in terms of their own infrastructure and manpower readiness. Under such situation, the BL in this course appeared to be based mainly on a business decision by the training provider to comply with government policies and make the business sustainable. 


\subsection{HR Management Learners: I know What to do After the Course!}

The HR course was mainly for the HR professionals in public service with at least five years of working experience. This course had three components of BL: Classroom, tech-enabled learning and workplace application to solve authentic HR issues at learners' own workplaces. The course lasted about two weeks with a final check-in for the sharing of their final project on authentic work-related issues four months after classroom teaching.

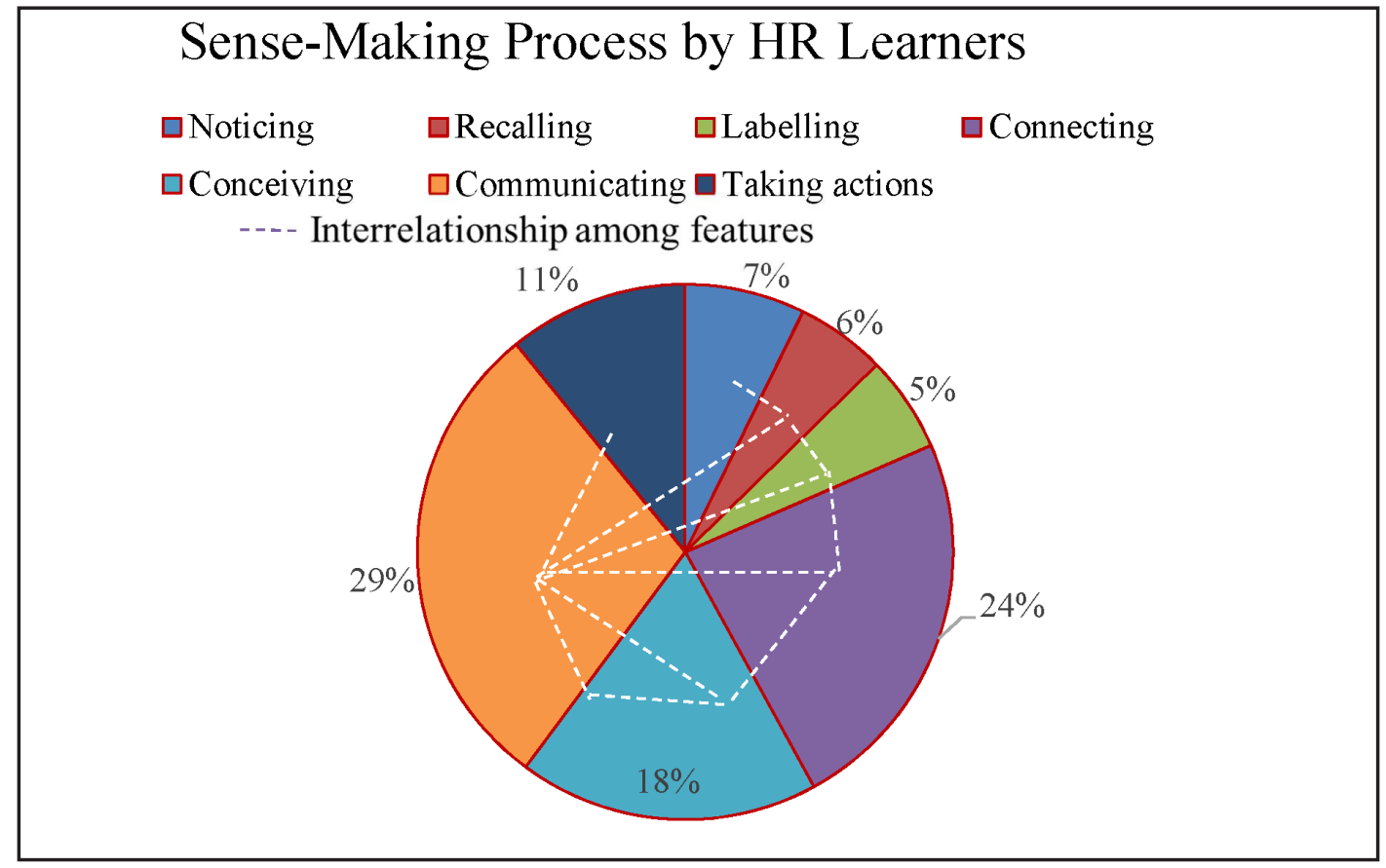

Figure 3: Sense-Making Process by HR Learners

Figure 3 shows that in the HR course, learners received more opportunities to make connections between theory and practices $(24 \%)$ and to conceive a more systemic understanding of the industry practice and job roles (18\%) throughout the entire course as compared with ICT learners. Comparatively, the rest of the features of sense-making were not so apparent in their sense-making process. In between these sense-making features, communicating with others was apparent too (29\%). Most importantly, HR leaners were given the greatest opportunities to take actions to apply what they have learned into their workplace practices (11\%).

The following excerpts from the HR learners' sharing are presented to show how the HR learners were making sense of the course in the deepest way as described in Figure 3.

During the course we had quite a lot of speakers from public service division so they came to share on different things, like the chief HRO shared on how the lands- 
cape is changing, and then as a HR practitioner, how our roles are changing. Traditionally people look at HR more of an administrative, support function, but going forward, the trend that has been happening is, they are looking at HR as a change agent, as a business partner at the same time, as a strategic partner at the same time. So, there are a lot of roles that HR is expected to play, to take on in the future, which was actually quite nicely shared with us and help us in a sense to prepare for that thinking. Then with the new different technologies like automation all these, so what is the role that HR is supposed to play. Then if you are talking about all these technologies that organisations are pushing out, the fourth industrial revolution, how can HR bring value to this wave of change? So, we must be at the frontier of it, that means to do so, we must be the ones who are able to embrace this change, and probably pilot some of these changes at our own offices before we can ask the rest of the organisations to adopt this change. (Wilkie, Learner from HR course)

The sharing by Wilkie above revealed that he gained a holistic and systemic understanding of the future expectation and roles of HR professionals. By attending the sharing sessions conducted by industry experts from both private and public sectors, he realised that HR professional's future role is beyond just doing administrative work, rather it involves many different roles in order to adapt to the future trend of work. Specifically, HR professionals may need to assume a frontier role to initiate the changes in the future of work. Such a trend was inevitable for future HR professionals, going beyond common HR practices in certain companies. Guest speakers contributed to helping Wilkie develop a more systemic understanding of the $\mathrm{HR}$ role. Besides, Willkie also valued the dialogic approach used in this course as shown in the excerpt below.

Mainly for this course I realised that the learning is in a sense two-way. The lecturer, actually I wouldn't call them lecturers. They were more like facilitators. So, they facilitate the discussion. It comes with their experience, what they have learnt before, and what are the work experiences that they can share with us [...]. Certain perspectives and then from our perspective we are able to contribute. And then bounce off the sharing from there. It is actually quite useful because the perspective that we have may be very different and then a lot of us come from different government agencies, so the background that we have are also quite different and the cases that we manage are also quite useful. So that has been very helpful. (Wilkie, Learner from HR course)

During participant observation, we noticed that classroom interactions were not only between facilitator and the learners, but also between peers. All the learners in this course were from different government agencies with different working background. By interacting with facilitators and peers, Wilkie realized that such communication or conversations turned out to 
be very helpful in terms of sharing the different perspectives on HR practices. Such communication gave him a more holistic view towards HR practices by enriching and broadening his understanding of standard HR practices in different government agencies. Pedagogical approaches and learner agency to initiate such communication in the learning process was quite crucial. The above example revealed clearly that adult educator in this course assumed a role more like a facilitator, rather than an authoritative lecturer dominating the classroom interaction with predetermined answers in didactic teaching (Walklin, 1990). At the same time, learners themselves also needed to take the initiative (and feel they are empowered to have the opportunities to do so) for the sharing of different HR practices in order to reach a broader and holistic understanding. The interview with the adult educator also revealed that he himself would also like to step back to give the classroom interactions more to the learners themselves to encourage their own sharing based on their own rich working experience.

In addition to the above features of sense-making process (connecting, conceiving and communicating), the HR course also provided quite good opportunities for the learners to apply what they have learned in the classroom to their workplace practices by doing a final project to address their real work issues (taking actions) as shown in the excerpt below.

So, for my project, I'm actually doing HR analytics. When you talk about HR analytics itself, it's that we want to have an understanding of the profile of the organization. So, like for example in my company, we have like 2,000-over staff. So, we want to have a better understanding of what's the age group, what's the length of service, what is the gender, is there a trend that we are looking at? Even like when they [...]. You may even be able to drill down to the number of MC (medical certificate) they have taken throughout the year and so on, to examine whether there are certain patterns. Then it's that [...], because when you take a look from analytics perspective, that it comes with a diagnostic, descriptive. Then what you can actually use such analysis is to help you to be able to make certain decisions. Because in the past, when people talk about the way HR makes decisions, it's like this [...], not really being supported by the data. But if you see the trend nowadays for HR movement, is we have gone big into like big data. We want to make more datadriven decisions. (Maisy, Learner from HR course)

At the time of interview, Maisy was at the stage of conceptualising the project. The process of conceptualisation by Maisy revealed that she was trying to use data analytics to analyse HR data she had to inform the HR decision-making in her own organization. She predicted what kind of analysis she could do with her own data and what kind of information she would like to gain from the data analysis. The final project was also part of the assessment for the course. Such a design element in the HR course helped learners make connections between theory 
and practices effectively to apply such analysis to make changes in the organizations (features of taking actions).

What appeared to be important in enabling such sense-making for HR learners was the access to experiences that immersed learners in the complexities of the work they are learning about, be it through guest speakers, their own work issues that they base their capstone project on or, complex simulated experiences that are linked to real work experiences of these learners. Another important element in the such sense-making was the dialogic nature in the delivery of this course, which encourages learners to share their thinking for adult educators to "diagnose needs, devise learning tasks, enhance understanding, assess progress, and guide students through the challenges they encounter" (Alexander, 2019, p.12).

\subsection{Why Seamless Sense-Making for HR Learners?}

As compared with ICT course, the HR course offered a seamless sense-making experience for the adult learners. The course created more opportunities for learners to contextualise their classroom learning to their workplaces. Again, such a seamless sense-making experience was created by the curriculum design and pedagogical practices shaped by the interplay between industry and TAE contexts. The HR learners' seamless sense-making experience is depicted in Figure 4.

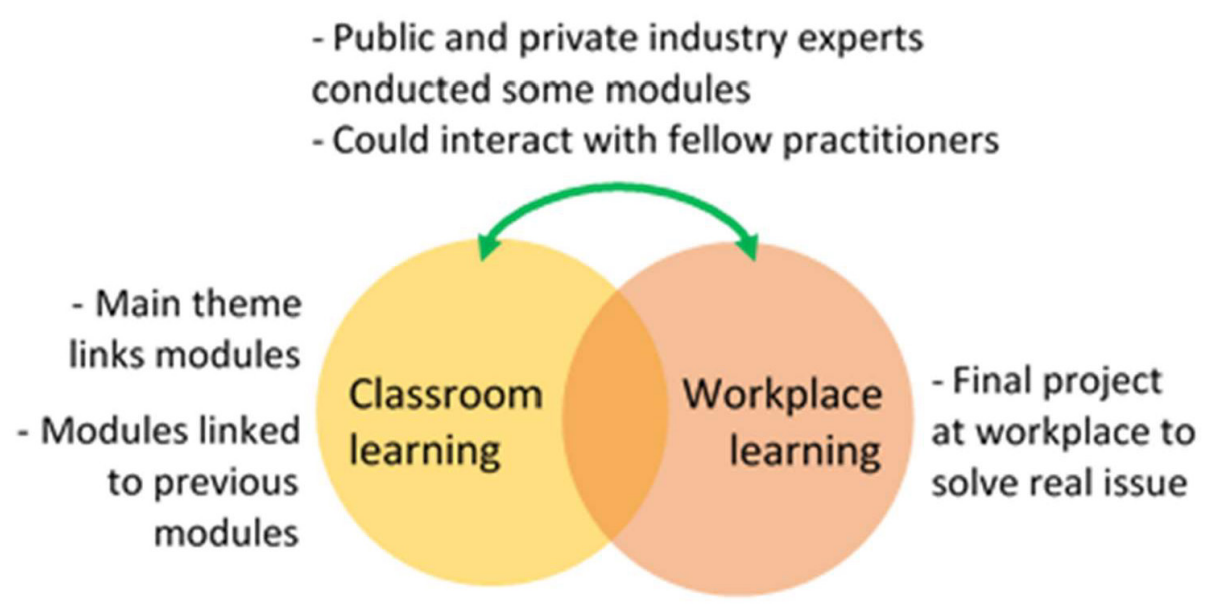

Figure 4: HR Learners' Seamless Sense-Making Experience in Blended Learning

The curriculum in this course was designed using a consistent narrative to form the backbone connecting and bridging different modules of the course. In addition, for each of the individual modules, there was a designated adult educator sitting through all the modules to link the module to the previous module as well as the module that came after the current 
one. Learners from different agencies sat together to share experiences, deepening their exposure to different HR practices. In addition, HR experts from both the public and private sectors were invited to conduct some sessions with rich industry examples and experiences in the course. Importantly, learners were required to select an issue in their own workplace and develop a project to address the issue. The linking of modules, access to industry experts, dialogue and interaction, authentic learning and assessment were important in helping learners make seamless sense of $\mathrm{HR}$ practices from different perspectives.

One of the unique features of this HR course as shared by the curriculum designer was that it deliberately mingled in the HR professionals with finance professionals to create communication between them and enable a better understanding of each other's daily practices. Finance professionals were from another course conducted by the training provider. This intentional aspect of curriculum design offered learners more exposure to what is happening at workplaces in order to prepare them for future challenges and industry transformation. One of the adult educators revealed that a need was rising in the corporate services for HR departments to move beyond being a supportive department dealing with administrative routines and backend work, but to actively build collaboration with other departments related to resources, such as finance department, in order to serve the common goal of the organization. The learners shared in a very comparative way between HR and Finance practices which could facilitate better collaboration when they go back to their own organisations and have to work with such professionals. Such an understanding could also help the learners step out of the box of HR work as merely a supportive administrative process to instead, nurture a growth mindset, to affect other departments' work. Such a design of the blended learning represented the most authentic and current practices for HR professionals. By mingling with the financial professional, these HR professionals would be able to foresee what will happen in real work setting in connection with their own work settings (connecting), so that they would be prepared by the training to take appropriate actions (taking actions) if they encounter the same situation in their own work settings.

Another important feature of the curriculum design of this HR course was the incorporation of a workplace-related assignment for learners to solve their workplace issues by applying whatever they have learnt from the course to solve a real issue at their own workplace. Such an assignment enabled the seamless sense-making because it enabled the learners to make connections between abstract theory and concrete practices (connecting). The example of using data analytics helped learners identify the gaps in their HR practices and make decisions on what changes they can make at their own workplace. Such an assignment helped them revisit their own workplace issues in the more scientific way and make more informed decisions to enable the transformation in the HR industry to meet the needs for such transformation. As a result, learners' sense-making experience in this course tended to be seamless as compared with ICT learners as they were able to use what they learnt in the 
course to make immediate application and take appropriate actions to address the issues at their workplace (taking actions). All the above shows that there was a clear purpose in the design and structuring of the course to help learners gain a deep understanding and make a seamless application of the current HR industry trends and practices in this blended learning.

Besides taking into consideration learners' needs in their curriculum design, the training providers' belief about teaching and learning (embodied in Adult Educator's pedagogical practices and training provider's learning facilities), also played a role in shaping the learners' seamless sense-making experience. The sharing from the adult educator in this course revealed that the training provider's belief in dialogic teaching (Alexander, 2019) and participative learning (Tsien \& Tsui, 2007) embodied in the classroom setting tended to enable the seamless sense-making for the learners. One of the adult educators shared that he firstly had to establish his role in the classroom as a facilitator, rather than an expert. This move signalled to the learners that they had to share and learn collaboratively based on their own rich experiences which were highly workplace-related and authentic, by which the learners were then able to contextualize and link what they had learnt in the course with their workplaces and made more seamless transition and application between classroom and workplace. Such a belief in teaching and learning and intended pedagogies benefited learners' sense-making experience in this course. One of the learners shared that such active participation in learning with highly authentic case scenarios reminded her of the daily HR routine of dealing with different colleagues in the organization. At the same time, this created an authentic learning environment for her to move seamlessly between classroom discussion and workplace communication.

\section{Mediation of Sense-Making}

As the examples illustrate, sense-making is not an individual activity happening solely in the minds of learners. It is apparent from the literature on sense-making and the data examined in this article that sense-making, is very much a social process, requiring access to opportunity to experiences that enable the use of all features of sense-making (Albolino et al., 2007; Malitis \& Christianson, 2014; Weick et al., 2005). The previous sections have focused on learners' sense-making, this section attempts to summarize and visualize how the interplay of these contextual factors may exert impact on sense-making.

Figure 5 illustrates the dynamic interplay in the TAE field between learning/curriculum design and facilitation of learning, and specific system issues and discourses, that influence sense-making opportunities. The nested ellipses in Figure 5 and the arrows between them, represent the interplay between learners' sense-making experiences and design and delivery (pedagogical practices) in blended learning, and the wider context of relations between training providers' interaction with industry. These interactions may either support or limit 
currency of practices and knowledge in a given industry, and system matters such as funding, accreditation and discourses in the TAE sector. None of the players are powerless in the face of system experiences. Maisy, for example, showed great agency in her identification of where to link theory and practices in order to both finish the assignment and also tackle the real issues at her workplaces. The HR training provider and their educators were also greatly agentic in developing close collaborations with the industry partners by inviting industry experts and incorporating highly authentic industry-related project to create the seamless sense-making for their learners. Both implicitly and explicitly, such close collaboration mediated adult educators' pedagogical practices whereby they built up a facilitative role to encourage the leaners to share their authentic experience with each other and, provide opportunity for learners with authentic experiences enabling the use of the features of sensemaking contributed to seamless sense-making.

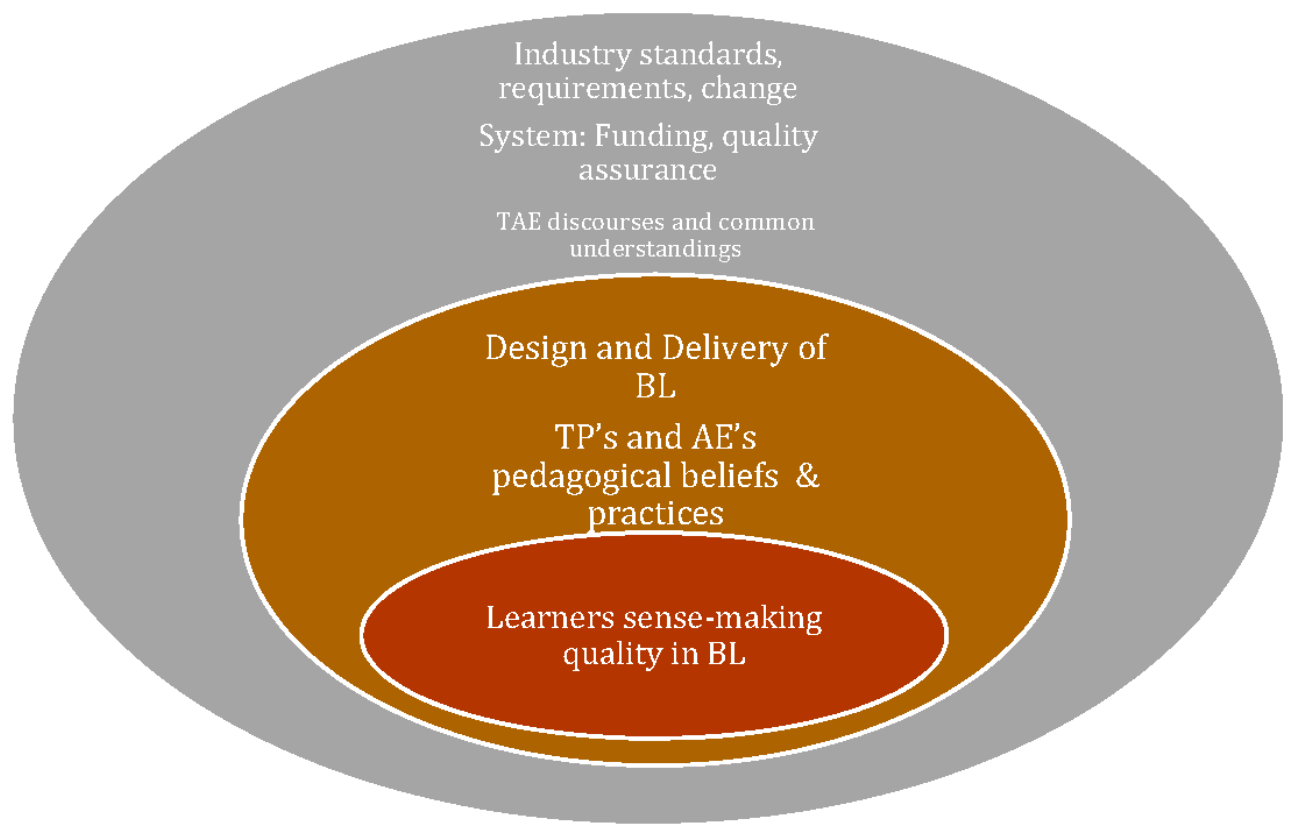

Figure 5: The Mediation of Sense-Making

Adult educators are the executors in delivering and facilitating blended learning courses; as such they are an immediate influence of adult learners' sense-making experience. Appropriate design and pedagogical practices can make a difference (Beard et al., 2004; Gleadow et al., 2015). As revealed by the findings, HR learners tend to experience seamless sense-making when they are offered more opportunities to share ideas, gain different perspectives from others and are exposed to different authentic workplace settings. Likewise, training providers have important contributions to make in ensuring learners to have access to opportunities 
to engage in all features of sense-making. Their work and relations with industry partners emerges as important for learners' seamless sense-making in BL. As part of their everyday practices and inherent in their business models, it is argued here that training providers have a responsibility to ensure close working relations with their industry, use such relations as a means for continuous feedback and updating of courses, currency of staff industry expertise and to create supportive and meaningful experiences across different learning spaces of classroom, work, online, practice spaces and so on.

\section{Conclusions}

Sense-making is prompted by experiencing ambiguity, a dilemma, uncertainty and so on (Dervin, 1998; Weick et al., 2005) and achieving the high quality of sense-making is a critical part of BL as discussed above. To achieve the high quality of sense-making in BL, the implications for curriculum and learning designers, and facilitators of learning seem obvious. Namely, that learners working with their own many experiences of unresolved ambiguities, uncertainties and so on, provides a clear starting point in the design of teaching and learning. Where this may not feasible, or not provide adequate challenge, then compiling complex authentic dilemmas and/or providing materials and problems that prompt engagement in all the features of sense-making is a ready alternative. Features of sense-making contributing to seamless sense-making tended to appear more when work experiences or highly authentic experiences are integral to the curriculum and when dialogic teaching (Alexander, 2019) and participative learning are encouraged (Tsien \& Tsui, 2007). However, what may seem obvious may be the exception rather than common practice. While institutional and policy responses may look initially to the professional expertise of educators and curriculum designers to address the issue, it is necessary to look beyond the issue of professionalisation. As evidenced in the accounts provided in this article, while curriculum and learning design and skilled facilitation can do much to address the opportunities for learners to use all features of sense-making, there are clear system issues and prevailing discourses and perceptions in the training and adult education sector that limit such possibilities.

System limitations and funding structures strongly mediate the degree to which learners' sense-making is fragmented or relatively seamless. Seamlessness of sense-making is enhanced when learning experiences are authentic (Chen et al., 2019), when there is constant feedback and communication from multiple sources (Alexander, 2019; Bi et al., 2020; Bound \& Chia, 2020; Walklin, 1990), and of course when materials are current. However, when there is no requirement for regular updating of course content or design, and classroom funding is most prevalent, then the profit-driven private training providers (the principal providers in Singapore) will respond accordingly. Discourses and common practices such as just placing the tech-enabled learning to convert the course into BL, impact negatively on design 
decisions; albeit that it does indeed result in uncertainty and a prompt for learners' sensemaking. However, this represents lost opportunities for development of deeper learning and development of expertise. An alternative is provision for iterative movement between different learning spaces (e.g. classroom, practice spaces, laboratories, online, work), but this would need to be supported across the system. Both private and public providers, are subject to sector discourse and quality assurance policies. At the time of writing, the government agency responsible for the training and adult education sector is putting in place reforms. Despite system limitations, there are curriculum and learning designers and training providers who do operate in the liminal spaces enabling use of all features of sense-making as a seamless experience as shown in the HR BL course. In these ways, adult educators can challenge the system from within.

\section{$8 \quad$ Limitations and Future Studies}

Factors mediating sense-making may be a good start for further research on how these different systemic and contextual factors are working together to influence and mediate the quality of sense-making in different BL settings both locally and internationally. The comparison of the two case studies shed promising light for future research on how important the interplay of dynamic industry and TAE contexts are in mediating the quality of adult learners' sense-making. It reveals that simply putting different BL components together may not the ultimate solution to enhance the adult learners' sense-making. The intricate design of these components and the embedded pedagogical approaches emerged as more crucial to ensure the occurrence of all sense-making features, particular those enabling connection and application, which are the key features for more seamless sense-making.

However, it may be challenging for the findings from only two case studies of sensemaking in BL in Singapore to be generalised broadly to international contexts with distinct industry and TAE contexts. Drawing on the findings of the present study, subsequent large-scale quantitative investigation on the correlations between these different systemic and contextual factors and adult learners' sense-making in various BL settings would be worth for future exploration. The quantitative investigation is expected to make contribution to a more holistic understanding of how system and contexts of BL mediate sense-making of adult learners in large sample of BL courses across more industry sectors. Practitioners and policy makers would also benefit greatly from such further quantitative exploration to inform their better practices in BL regulation and execution. 


\section{Acknowledgement}

This study is funded by SkillsFuture Singapore (SSG). Helen Bound (Institute for Adult Learning, SUSS, Singapore) and Fadhil Mohamad substantially contributed to this study.

\section{References}

Ahmad, N., \& Orion, P. (2010). Smartphones make IBM smarter, but not as expected. American Society for Training and Development. https://www.td.org/magazines/td-magazine/smartphonesmake-ibm-smarter-but-not-as-expected

Albolino, S., Cook, R., \& O’Connor, M. (2007). Sensemaking, safety, and cooperative work in the intensive care unit. Cognition, Technology and Work, 9(3), 131-137.

Alexander, R. J. (2019). Whose discourse? Dialogic pedagogy in a post-truth world. Dialogic Pedagogy: An International Online Journal, 7. Https://doi.org/10.5195/dpj.2019.268

Beard, L. A., Harper, C., \& Riley, G. (2004). Online versus on-campus instruction: Student attitudes \& perceptions. TechTrends, 48(6), 29-31.

Bhatti, M. A., \& Kaur, S. (2010). The role of individual and training design factors on training transfer. JournalofEuropean IndustrialTraining,34(7),656-672.https://doi.org/10.1108/03090591011070770

Bi, X. F., Bound, H., Mohamed, F., Cai, V., \& Chuen, K. H. (2020). Understanding adult learners' sensemaking to inform pedagogical innovations in blended learning. Institute for Adult Learning.

Bound, H., \& Chia, A. (2020). The six principles of learning design. Institute for Adult Learning.

Bound, H., \& Lin, M. (2011). Singapore Workforce Skills Qualification (WSQ), workplace learning and assessment (Stage I and II). IAL.

Chen, Z., Ramos, C., Phua, L. D., \& Cheng, S. C. (2019). Training and adult education landscape in Singapore: Characteristics, challenges and policies. Institute for Adult Learning.

Dervin, B. (1998). Sense-making theory and practice: An overview of user interests in knowledge seeking and use. Journal of Knowledge Management, 2(2), 1-11.

Edwards, A. (2010). Knowledge work at practice boundaries. In A. Edwards (Ed.), Being an expert professional practitioner, the relational turn in expertise. Professional and Practice-based Learning, 3. (pp. 41-60). Springer. https://doi.org/10.1007/978-90-481-3969-9_3

Gleadow, R., Macfarlan, B., \& Honeydew, M. (2015). Design for learning - a case study of blended learning in a science unit. F1000Research, 4.

Hammersley, M. (2010). Ethnography. In P. Peterson, E. Baker \& B. McGaw (Eds.), International encyclopedia of education (3rd ed., pp. 386-391). https://doi.org/10.1016/B978-0-08-0448947.01533-5

Harverly, C., Barton, A, C., Schwarz, C. V., \& Braaten, M. (2020). Making space: How novice teachers create opportunities for equitable sense-making in elementary science. Journal of Teacher Education, 71(1), 63-79.

Institute for Adult Learning. (2016). Blending classroom with work and technology: How to design a blended curriculum. Institute for Adult Learning.

Kintu, M. J., Zhu, C., \& Kagambe, E. (2017). Blended learning effectiveness: The relationship between student characteristics, design features and outcomes. International Journal of Educational Technology in Higher Education, 14(7). https://doi.org/10.1186/s41239-017-0043-4 
Koh, E., Shibani, A., Tan, J. P. L., \& Hong, H. (2016). A pedagogical framework for learning analytics in collaborative inquiry tasks: An example from a teamwork competency awareness program. Proceedings of the Sixth International Conference on Learning Analytics \& Knowledge (pp. 74-83). ACM.

Kolb, D. (1984). Experiential Learning. Prentice Hall.

Koponen, T., Tedre, M., \& Vesisenaho, M. (2011). An analysis of the state and prospects of e-learning in developing countries. International Journal of Education and Development using Information and Communication Technology, 9(2), 19-36.

Korhonen, A.-M., Ruhalahti, S., Lakkala, M., \& Veermans, M. (2020). Vocational student teachers' self-reported experiences in creating eportfolios. International Journal for Research in Vocational Education and Training, 7(3), 278-301. https://doi.org/10.13152/IJRVET.7.3.2

Lave, J. (1988). Cognition in practice: Mind, mathematics and culture in everyday life. Cambridge University Press.

Malitis, S., \& Christianson, M. (2014). Sensemaking in organizations: Taking stock and moving forward. The Academy of Management Annals, 6(1), 57-125.

Moran, D. (2000). Introduction to Phenomenology. Routledge.

Maskiewicz, A. C., \& Winters, V. A. (2012). Understanding the co-construction of inquiry practices: A case study of a responsive teaching environment. Journal of Research in Science Teaching, 49(4), 429-464. https://doi.org/10.1002/tea.21007

Owen, C. (2009a). Near-misses and mistakes in risky-work: An exploration of work practices in High-3 environments. In C. Owen, P. Beguin \& G. Wackers (Eds.), Risky work environments: Reappraising human work within fallible systems (pp. 262-297). Ashgate.

Owen, C. (2009b). Toward developmental work in complex and fallible systems. In C. Owen, P. Beguin \& G. Wackers (Eds.), Risky work environments: Reappraising human work within fallible systems (pp. 298-314). Ashgate.

Owen, C. (2017). Enhancing learning in the workplace. Paper presented at IAL Expert Roundtable.

Piccoli, G., Ahmad, R., \& Ives, B. (2001). Web-based virtual learning environments: A research framework and a preliminary assessment of effectiveness in basic IT skill training. MIS Quarterly, 25(4), 401-426.

Scardamalia, M., \& Bereiter, C. (2015). Knowledge building: Theory, pedagogy, and technology. In R. K. Sawyer (Ed.), The Cambridge handbook of the learning sciences (2ed ed., pp. 397-417). Cambridge University Press.

Shorey, S., Siew, A. L., \& Ang, E. (2018). Experiences of nursing undergraduates on a redesigned blended communication module: A descriptive qualitative study. Nurse Education Today, 61, $77-82$.

Strayer, J. F., Hart, J. B., \& Bleiler, S. K. (2015). Fostering instructor knowledge of student thinking using the flipped classroom. Primus, 25(8), 724-735.

Tsien, T. B. K., \& Tsui, M.-S. (2007). A participative learning and teaching model: The partnership of students and teachers in practice teaching. Social Work Educationr, 26(4), 348-358. https://doi. org/10.1080/02615470601081654

Velada, R., Caetano, A., Michel, J. W., Lyons, B. D., \& Kavanagh, M. J. (2007). The effects of training design, individual characteristics and work environment on transfer of training. International Journal of Training and Development, 11(4), 282-294.

Walklin, L. (1990). Teaching and learning in further and adult education. Nelson Thornes. 
Weick, K. (1995). Sense-making in organizations. Sage.

Weick, K. E., Sutcliffe, K. M., \& Obstfeld, D. (2005). Organizing and the process of sensemaking. Organization Science, 16(4), 409-421.

Willging, P. A., \& Johnson, S. D. (2009). Factors that influence students' decision to drop-out of online courses. Journal of Asynchronous Learning Networks, 13(3), 115-127.

Woodruff, S. D. (2018). Phenomenology. In E. N. Zalta (Ed.), The Stanford encyclopedia of philosophy. https://plato.stanford.edu/archives/sum2018/entries/phenomenology/

\section{Biographical Note}

Dr Bi Xiaofang is a Senior Researcher with Institute for Adult Learning (IAL), Singapore University of Social Sciences. Her research interests include blended learning, workplace learning and skills development. Xiaofang has a background in educational research on pedagogy and curriculum design. She has years of experience in conducting both qualitative and quantitative educational research in both PET (Pre-employment) and CET (Continuing Education and Training) sectors. 